\title{
LA DEUDA LABORAL DE LAS EMPRESAS EN CONCURSO: LA LEY CONCURSAL ESPAÑOLA Y EL TRIBUNAL DE LA UE
}

\author{
RAMÓn BorJabad BeLlido \\ Director de la EURL \\ Coordinador del Máster Universitario \\ en Dirección y Gestión Laboral
}

DOI: $10.1387 /$ lan-harremanak.15405

\section{ABSTRACT}

Jueces de lo Mercantil y Secretarios Judiciales de Cataluña habian acordado antes de la entrada en vigor de la modificación de la Ley concursal en septiembre de 2014 que la venta de la unidad productiva se realizaría libre de cargas, sólo el adquirente que se subrogase en parte o en todos los contratos laborales, se subrogaría en las obligaciones pendientes derivadas de dichos contratos, excepción en la parte que satisfaga el FOGASA cuando se prevea expresamente y se concretaba que el adquirente no asumiría la responsabilidad por las deudas laborales de los contratos de trabajo respecto de los que no se hubiera subrogado, ni de las deudas tributarias ni de la Seguridad Social, sin embargo las modificaciones legales siguientes volvian a crear dudas, al igual que el Tribunal de Justicia de la Unión Europea.

Palabras clave: Sustituir todas las palabras por: concurso de acreedores, insolvencia, deuda laboral, Seguridad Social y Derecho comunitario.

\footnotetext{
1 EURL: Escuela Universitaria de Relaciones Laborales de Lleida (EURL), centro adscrito a la Universidad de Lleida.
} 
Judges of the "Mercantile» (commerce) and Judicial Secretaries of Catalonia (Autonomous Community of Spain) had agreed before the entry into force of the modification of the Law concursal (Bankruptcy) in September, 2014 that the sale of the productive unit would realize free of loads, only the buyer who was replaced partly or in all the labor contracts, it would be replaced in the hanging obligations derived from the above mentioned contracts, exception in the part that the FOGASA satisfies when it is foreseen expressly and was making concrete that the buyer would not assume the responsibility for the labor debts of the contracts of work respect of that it had been replaced, neither of the payable taxes nor of the National Health Service, nevertheless the legal following modifications were returning to create doubts, as the Court of Justice of EU.

Key Words: Bankruptcy, insolvency, labour debt, Social Security y EU Court of Justice. 


\section{Introducción}

Este trabajo pretende realizar una aproximación a la llamada «deuda laboral» de empresas en concurso y su "herencia», desde la Directiva 80/987/CEE ${ }^{2}$ del Consejo de 20 de octubre de 1980, sobre la aproximación de las legislaciones de los Estados Miembros relativas a la protección de los trabajadores asalariados en caso de insolvencia del empresario, hasta el Real Decreto-Ley 1/2015, de 27 de febrero, de mecanismo de segunda oportunidad, reducción de carga financiera y otras medidas de orden social, pasando por, entre otras cuestiones, el Auto del Tribunal de Justicia de la Unión Europea (Sala sexta) de 28 de enero de 2015, en el asunto C-688/13 que tuvo por objeto una petición de decisión prejudicial planteada, con arreglo al artículo 267 TFUE, por el Juzgado de lo Mercantil n. ${ }^{\circ} 3$ de Barcelona.

\section{La Directiva del Consejo de las Comunidades Europeas, la Ley Concursal Española y las Instrucciones de la Tesorería General de la Seguridad Social de España}

El 20 de octubre de 1980, la Directiva del Consejo 80/987/CEE, sobre la aproximación de las legislaciones de los Estados Miembros relativas a la protección de los trabajadores asalariados en caso de insolvencia del empresario consideraba que eran necesarias normas para la protección de los trabajadores asalariados en caso de insolvencia del empresario, especialmente para garantizar el pago de sus créditos impagados, teniendo en cuenta la necesidad de un desarrollo económico y social equilibrado en la Comunidad, además consideraba también que subsistían diferencias entre los Estados miembros en cuanto al alcance de la protección de los trabajadores asalariados en éste ámbito y que sería conveniente reducir esas diferencias, por lo que, procedía promover la aproxima-

2 Directiva 80/987/CEE del Consejo, de 20 de octubre de 1980, sobre la aproximación de las legislaciones de los Estados Miembros relativas a la protección de los trabajadores asalariados en caso de insolvencia de empresario. Diario Oficial n. ${ }^{\circ}$ L283 de 28/20/1980 pp. 0023-0027. Edición especial en espańol: Capítulo 05 tomo 2p. 0219. 
ción de las legislaciones en esta materia por vía del progreso y con arreglo al artículo 117 del Tratado 3 .

Así la situación, la Sección III de la Directiva trató el tema de la Seguridad Social en sus artículos 6,7 y 8.

El primer artículo determinaba que los Estados miembros podrían prever que los artículos 3, 4 y 5 de la Directiva, es decir, aquellos que obligaba a los Estados a adoptar medidas necesarias a fin de que las instituciones de garantía asegurasen el pago de los créditos impagados de los trabajadores asalariados, que además tuvieran la facultad de limitar la obligación de pago de las instituciones de garantía y que fijaran las modalidades de la organización, de la financiación y del funcionamiento de las instituciones de garantía, no se apliquen a las cotizaciones debidas en virtud de los regímenes legales nacionales de seguridad social o de los regímenes complementarios de previsión profesionales o interprofesionales que existan independientemente de los regímenes legales nacionales de seguridad social.

En el segundo se determinó que los Estados miembros adoptarían las medidas necesarias para garantizar que el impago de cotizaciones obligatorias adeudadas por el empresario a sus instituciones de seguros, antes de sobrevenir su insolvencia, en virtud de los regímenes legales nacionales de seguridad social, no tuvieran efectos perjudiciales en el derecho a prestaciones del trabajador asalariado respecto a tales instituciones de seguros, a medida en que las cotizaciones salariales se hubieran descontado previamente de los salarios abonados.

En el tercer artículo se estableció que los Estados miembros se asegurarían de que se adoptasen las medidas necesarias para proteger los intereses de los trabajadores asalariados y de las personas que ya hayan dejado la empresa o el centro de actividad del empresario, en la fecha en que se produce la insolvencia de éste, en lo que se refiere a sus derechos adquiridos, o sus derechos en curso de adquisición, a prestaciones de vejez, incluidas las prestaciones a favor de los supervivientes, en virtud de regímenes complementarios de previsión profesionales o interprofesionales que existan independientemente de los regímenes legales nacionales de seguridad social.

Con la entrada en vigor el día 1 de septiembre de 2004 de la Ley concursal que derogaba las instituciones de la quiebra y la suspensión de pagos, se dio paso a una posible transmisión de empresas en situación de insolvencia con concurso declarado por el Juez de lo Mercantil. La posible continuidad de las empresas

3 La Directiva 80/987/CEE tiene en consideración, concretamente, el artículo 100 del Tratado: 1. Sin perjuicio de los demás procedimientos previstos en el presente Tratado, el Consejo, por mayoría cualificada y a propuesta de la Comisión, podrá decidir medidas adecuadas a la situación económica...". 
fue objetivo perseguido por la Ley concursal, facilitando al posible adquirente de la empresa en concurso la adquisición de sus bienes o derechos o de determinadas unidades productivas. La Ley estableció que ése posible adquirente debía asumir la obligación de pagar los créditos a los acreedores con la «quita y espera» que se estableciera en el Convenio con los acreedores. La Ley estableció a favor de la continuidad empresarial, la exención del régimen general de responsabilidad del adquirente por deudas tributarias de la empresa adquirida, sin embargo, la Ley no concedió a las «deudas laborales» las mismas ventajas por lo que el adquirente de la empresa respondía de las obligaciones laborales nacidas con anterioridad a la transmisión de la misma. La posible solución se establecía al permitir la Ley que en el mismo procedimiento se realizaran expediente de modificación, suspensión o extinción de contratos de trabajo, siendo ello lo que debería realizar el adquirente para adquirir la empresa, extinguiendo contratos de trabajo cuya liquidación iría a cargo de los activos de la empresa en concurso, finalmente la Ley facultaba al Juez para poder acordar, en fase de liquidación, que el adquirente de la empresa no se subrogase en los salarios o en las indemnizaciones pendientes de pago en aquella parte que se hubiera devengado antes de la transmisión de la empresa y que fueran pagadas por el Fondo de Garantía Salarial.

En fecha 4 de marzo de 2013, la Dirección General de la Tesorería General de la Seguridad Social, a propuesta de la Subdirección General de Procedimientos Ejecutivos y Especiales de Recaudación, previo informe de la Subdirección General de Ordenación e Impugnaciones y de la Secretaría General-Inspección de Servicios, emitió una circular, en la que establecía una serie de Instrucciones entre las cuales y concretamente en la novena que habla de la liquidación establecía que de conformidad con lo dispuesto en el artículo 149.2 de la Ley Concursal cuando se enajenase en la fase de liquidación una entidad económica que mantenga su identidad, entendida como un conjunto de medios organizados a fin de llevar a cabo una actividad económica esencial o accesoria, se considerará, a los efectos laborales, que existe sucesión de empresa, por lo que se seguirá el procedimiento recaudatorio, en su caso, contra los posibles responsables solidarios del concursado por los importes no satisfechos en la liquidación. En consecuencia, seguía manifestando la instrucción, debían efectuarse observaciones al Plan de liquidación que exonerase de responsabilidad por deudas a la Seguridad Social al adquirente de la empresa en concurso con tal motivo, dando traslado al Servicio Jurídico Delegado Provincial para ello.

\section{Enajenación de una entidad económica en la Ley Concursal española y la deuda con la Seguridad Social}

Es evidente que la declaración del concurso en ningún caso interrumpe obligatoriamente la actividad de la empresa o del profesional, aunque la fina- 
lidad del concurso, sin perjuicio de los efectos que produce sobre las facultades patrimoniales de éste, pero goza el juez del concurso de amplias potestades para acordar el cierre de sus oficinas, establecimientos o explotaciones, e incluso, cuando se trate de una actividad empresarial, el cese o la suspensión, total o parcial, de ésta, previa audiencia del deudor y de los representantes de los trabajadores.

La Ley Concursal concede al juez del concurso una amplia discrecionalidad en el ejercicio de sus competencias, lo que contribuye a facilitar la flexibilidad del procedimiento y su adecuación a las circunstancias de cada caso. Las facultades discrecionales del juez se manifiestan en cuestiones tan importantes como la adopción de medidas cautelares con anterioridad a su declaración o a la entrada en funcionamiento de la administración concursal; la ampliación de la publicidad que haya de darse a la declaración de concurso y a otras resoluciones de interés de terceros; la acumulación de concursos; el nombramiento, la separación y el régimen de funcionamiento de los administradores concursales; la graduación de los efectos de la declaración de concurso sobre la persona del deudor, los acreedores y los contratos; la aprobación del plan de liquidación o el régimen de pago de crédito.

Las excepciones que la ley admite son positivas o negativas, en relación con los créditos ordinarios. Las primeras se concretan en los privilegios, especiales o generales, por razón de las garantías de que gocen los créditos o de la causa o naturaleza de éstos. A los acreedores privilegiados, en principio, sólo afectará el convenio con su conformidad y, en caso de liquidación, se les pagará con prioridad respecto de los ordinarios. Pero esos privilegios se reducen en número e incluso se limitan en su cuantía a algunos de los tradicionalmente reconocidos, como los tributarios y los de cuotas de la Seguridad Social (hasta el 50 por ciento de su importe en cada caso).

El convenio es la solución normal del concurso, que la ley fomenta con una serie de medidas, orientadas a alcanzar la satisfacción de los acreedores a través del acuerdo contenido en un negocio jurídico en el que la autonomía de la voluntad de las partes goza de una gran amplitud.

También es flexible la ley en la regulación del contenido de las propuestas de convenio, que podrá consistir en proposiciones de quita o de espera, o acumular ambas; pero las primeras no podrán exceder de la mitad del importe de cada crédito ordinario, ni las segundas de cinco años a partir de la aprobación del convenio, sin perjuicio de los supuestos de concurso de empresas de especial trascendencia para la economía y de presentación de propuesta anticipada de convenio cuando así se autorice por el juez. Se admiten proposiciones alternativas, como las ofertas de conversión del crédito en acciones, participaciones o cuotas sociales, o en créditos participativos. Lo que no admite la ley es que, a través de cesiones de bienes y derechos en pago o para pago de créditos u otras 
formas de liquidación global del patrimonio del concursado, el convenio se convierta en cobertura de solución distinta de aquella que le es propia. Para asegurar ésta y la posibilidad de cumplimiento, la propuesta de convenio ha de ir acompañada de un plan de pagos.

La finalidad de conservación de la actividad profesional o empresarial del concursado puede cumplirse a través de un convenio, a cuya propuesta se acompañará un plan de viabilidad. Aunque el objeto del concurso no sea el saneamiento de empresas, un convenio de continuación puede ser instrumento para salvar las que se consideren total o parcialmente viables, en beneficio no sólo de los acreedores, sino del propio concursado, de los trabajadores y de otros intereses. El informe preceptivo de la administración concursal es una garantía más de esta solución.

Llegados a este punto debemos recordar el concepto de compraventa de empresa ${ }^{4}$, teniendo en cuenta que la transmisión, en este caso, no tiene porque ser global ya que pueden transmitirse diferentes pero determinadas partes de la misma, siempre y cuando esas partes constituyan unidades productivas.

La transmisión que aquí nos ocupa puede realizarse vía convenio o vía liquidación. En la primera se realiza mediante la aprobación del convenio cuya finalidad es la continuidad del ejercicio de la actividad del concursado, pudiendo ser continuada por el propio concursado o por un tercero. En la segunda vía la de liquidación se produce cuando la transmisión de la empresa o de la unidad productiva se realiza en la liquidación del procedimiento concursal, ya que la finalidad aquí es la liquidación de la masa activa del concursado para aplicarla a cubrir las deudas.

La cuestión fundamental de todo el procedimiento es realmente la continuación de la actividad empresarial o profesional que se venía realizando con anterioridad al concurso y la obligación del adquirente será la de conservar y mantener la empresa bien en su totalidad bien en sus unidades o partes, ahora bien, el derecho de información es un elemento clave en el Concurso y ello tanto si se produce la transmisión en el Convenio como en la Liquidación. En el caso del Convenio la información aparece en la propuesta y documentación anexa, el informe de la administración concursal y en la oferta de adquisición de la empresa concursada o de la unidad productiva y en el caso de liquidación en el plan de liquidación y en la oferta de adquisición de la empresa concursada o de unidad/ unidades productivas.

${ }^{4}$ Primitivo Borjabad Gonzalo, en Derecho Mercantil Vol. I, 3.a edición, pag. 77, EURL, Lleida 1998, expresa que por la compraventa de empresa, se transmite del vendedor al comprador, la titularidad de cada una de las relaciones jurídicas que ligan al primero de ellos con cada uno de los elementos de que aquélla se compone. 
Es en este momento donde aparece la posible o no subrogación de la deuda de la seguridad social por parte del adquirente y ello porque en relación a los créditos de la seguridad social no existía ni en la ley concursal ni en otra normativa algún elemento que pudiera evitar el artículo $127^{5}$ del Texto Refundido de la Ley General de la Seguridad Social ${ }^{6}$. Dicho esto las resoluciones de los juzgados de lo mercantil no han sido uniformes hasta la fecha, ya que existen resoluciones de Audiencias que han sido favorables a la no subrogación de la deuda de la seguridad social por parte del adquirente ${ }^{7}$, pero también otras que han sido favorables a la postura mantenida por la Tesorería General de la Seguridad Social. ${ }^{8}$

5 Apartado 2 del artículo 127. «En los casos de sucesión en la titularidad de la explotación, industria o negocio, el adquirente responderá solidariamente con el anterior o con sus herederos del pago de las prestaciones causadas antes de dicha sucesión. La misma responsabilidad se establece entre el empresario cedente y cesionario en los casos de cesión temporal de mano de obra, aunque sea a título amistoso o no lucrativo.»

6 Real Decreto Legislativo 1/1994, de 20 de junio, por el que se aprueba el Texto Refundido de la Ley General de la Seguridad Social (Vigente hasta el 01 de Junio de 2015).

7 Véase por ejemplo: Roj: AJM M 19/2013-ECLI:ES:JMM:2013:19A; Id Cendoj: 28079470062013200002; Órgano: Juzgado de lo Mercantil; Sede: Madrid; Sección: 6 N.o de Recurso: 5/2012; Procedimiento: Apelación, Concurso de acreedores; Ponente: FRANCISCO JAVIER VAQUER MARTIN; Tipo de Resolución: Auto, en la que se dice textualmente: «En este sentido, el adquirente de la unidad productiva no asumirá/se subrogará en las mencionadas deudas con Hacienda, Seguridad Social y salarios e indemnizaciones pendientes de pago de los trabajadores (art. 149.2 LC ), que permanecerán de cuenta exclusiva de TCCW . En este sentido, el Auto de la Audiencia provincial de Barcelona (sección 15. a), de fecha 29 de noviembre de 2010 ,, que taxativamente establece que «el crédito de la Seguridad Social, como cualquier otro crédito que no sea propiamente laboral, no resulta exigible al adquirente de la unidad productiva, y ello sin necesidad de que se pronuncie expresamente en tal sentido la normativa de la Seguridad Social».

8 Véase por ejemplo: Roj: AAP VI 209/2011-ECLI:ES:APVI:2011:209A; Id Cendoj: 01059370012011200076; Órgano: Audiencia Provincial; Sede: Vitoria-Gasteiz; Sección: 1

N. ${ }^{\circ}$ de Recurso: 623/2010; N. ${ }^{\circ}$ de Resolución: 47/2011; Procedimiento: CIVIL; Ponente: MARIA MERCEDES GUERRERO ROMEO; Tipo de Resolución: Auto, en la que se dice textualmente: "Cierto es que hay alguna resolución judicial que ha acudido a la idea de la prejudicialidad para justificar un pronunciamiento respecto al alcance de la sucesión de empresas y a ellas se ha aludido en los diferentes escritos que se han presentado por las partes. Sin embargo, no se comparte dicho criterio. Es cierto que el artículo 9 de la LC extiende la jurisdicción del juez del concurso a todas las cuestiones prejudiciales administrativas o sociales directamente relacionadas con el concurso o cuya resolución sea necesaria para el buen desarrollo del procedimiento concursal. Sin embargo, tal precepto no ampara el pronunciamiento que se solicita. En primer término puesto que no se considera que tal pronunciamiento tenga el grado de vinculación con el procedimiento concursal que se refiere el precepto máxime atendiendo a que las consecuencias, en su caso, y la proyección del pronunciamiento interesado relativo al alcance de la subrogación de él. En segundo lugar, por el carácter inocuo e irrelevante de dicho pronunciamiento que de conformidad con el art. 42.2 LEC no surtiría efecto fuera del procedimiento concursal. Por ello, no obstaría la posterior reclamación de la TGSS con los recursos legalmente establecidos, ni vincularía la decisión a adoptar por el órgano judicial competente, que como se ha señalado no es el mercantil. ... Por lo anterior, y entendiendo acertadas las consideraciones iniciales que la TGSS sostiene en el párrafo primero de la alegación cuarta de su escrito, se considera que este juzgado no es competente para resolver sobre la purga de responsabilidades a que se refiere la administración concursal en su escrito solicitando autorización judicial, por lo que, en aplicación del art. 149.2 LC se acuerda autorizar la enajenación del conjunto productivo 


\section{El Real Decreto-Ley 11/2014 y la enajenación de unidades productivas}

El Real Decreto-ley 4/2014, de 7 de marzo, por el que se adoptaban medidas urgentes en materia de refinanciación y reestructuración de deuda empresarial flexibilizó el régimen de los convenios pre-concursales de acuerdo con algunas premisas básicas, siendo la primera de ellas la de considerar que la continuidad de las empresas económicamente viables es beneficiosa no sólo para las propias empresas, sino para la economía en general y, muy en especial, para el mantenimiento del empleo y la segunda de las premisas era acomodar el privilegio jurídico a la realidad económica subyacente, pues muchas veces el reconocimiento de privilegios carentes de fundamento venía a ser el obstáculo principal de los acuerdos pre-concursales.

Se adoptaron medidas para flexibilizar la transmisión del negocio del concursado o de alguna de sus ramas de actividad y se introdujo una previsión novedosa, con el artículo 134.3, que también tenía precedente en el Real Decretoley 4/2014, de 7 de marzo, sobre la posibilidad de arrastre de determinados créditos con privilegio general o especial, incluso en la parte cubierta por el valor de la garantía. Aunque para ello se exige un doble requisito: además de unas mayorías aún más reforzadas, el que el acuerdo sea adoptado por acreedores de la misma clase, introduciéndose por primera vez en nuestro ámbito concursal esta consideración que ya tiene precedentes en derecho comparado, y en los acuerdos pre-concursales de la disposición adicional cuarta que afectan a los acreedores de pasivos financieros. Para ello se distinguen cuatro clases de acreedores, cada uno de los cuales reúne características propias que justifican un tratamiento específico en el seno del concurso. En primer lugar, los acreedores de derecho laboral; en segundo lugar, los acreedores públicos; en tercer lugar, los acreedores financieros; y finalmente, el resto.

de la concursada, que será considerada como sucesión de empresa a los efectos laborales, sin que el adquirente se subrogue en la parte de la cuantía de los salarios o indemnizaciones pendientes de pago anteriores a la enajenación que sea asumida por el FOGASA de conformidad con el art. 33 ET.»

El precepto se refiere a los efectos que pueden producirse en el caso de sucesión de empresa en el ámbito laboral. En ese supuesto el juez del concurso en el momento de autorizar la operación de venta de la unidad productiva, puede eximir al nuevo adquirente de la empresa o unidad productiva de la obligación de abonar el importe de los salarios e indemnizaciones que conforme al art. 33 ET pagó el FOGASA como consecuencia del concurso. El juez del concurso puede liberarle de esta obligación.

El precepto no se refiere a otros efectos que puedan derivarse del concurso, lo que significa que el juez del concurso no puede intervenir en la fijación del resto de las consecuencias de la enajenación puesto que no se le faculta para ello en el art. 149 LC. Así, partiendo de que exista sucesión de empresas, si la TGSS reclama pagos atrasados al nuevo adquirente deberá solucionarse en la vía adecuada, este precepto no indica que el nuevo adquirente quede exento de los pagos debidos por el concursado a la TGSS. En esta línea la Sala comparte la interpretación que realiza el Juzgado de lo Mercantil de Santander.» 
En materia de liquidación se modificaron determinados preceptos del capítulo II del título V de la Ley Concursal con el objeto de facilitar el desarrollo de esta fase de procedimiento concursal, pretendiendo con todo ello, garantizar en lo posible la continuación de la actividad empresarial, facilitando, fundamentalmente, la venta del conjunto de los establecimientos y explotaciones del concursado o de cualesquiera otras unidades productivas.

Se introdujo la subrogación ipso iure del adquirente en los contratos y licencias administrativas de que fuera titular el cedente (artículo 146 bis) y se arbitraron los mecanismos de exención de responsabilidad por deudas previas, salvo en determinados casos especiales que por su singularidad seguían mereciendo, como dice la propia norma, una especial tutela, como es el caso de las deudas frente a la Seguridad Social o a los trabajadores.

Con todo ello podríamos hablar de lo que podría ser más importante, es decir, de los efectos que tiene la venta de la/s unidad/es productiva/s. El nuevo artículo 146 bis habla precisamente de las especialidades de la transmisión de las unidades productivas en él se establece en primer lugar que en caso de transmisión de unidades productivas, se cederán al adquirente los derechos y obligaciones derivados de contratos afectos a la continuidad de la actividad profesional o empresarial cuya resolución no hubiera sido solicitada y el adquirente se subrogará en la posición contractual de la concursada sin necesidad de consentimiento de la otra parte. La cesión de contratos administrativos se producirá de conformidad con lo dispuesto por el artículo 226 del texto refundido de la Ley de Contratos del Sector Público, aprobado por el Real Decreto Legislativo 3/2011, de 14 de noviembre. En segundo lugar también se cederán aquellas licencias o autorizaciones administrativas afectas a la continuidad de la actividad empresarial o profesional e incluidas como parte de la unidad productiva, siempre que el adquirente continuase la actividad en las mismas instalaciones. En tercer lugar dice el propio artículo que lo dispuesto en los dos apartados anteriores (primer y segundo lugar) no será aplicable a aquellas licencias, autorizaciones o contratos en los que el adquirente haya manifestado expresamente su intención de no subrogarse, pero, ello sin perjuicio, a los efectos laborales, de la aplicación de lo dispuesto en el artículo $44^{9}$ del Estatuto de los Trabajadores en

9 Artículo 44 La sucesión de empresa: 1. El cambio de titularidad de una empresa, de un centro de trabajo o de una unidad productiva autónoma no extinguirá por sí mismo la relación laboral, quedando el nuevo empresario subrogado en los derechos y obligaciones laborales y de Seguridad Social del anterior, incluyendo los compromisos de pensiones, en los términos previstos en su normativa específica, y, en general, cuantas obligaciones en materia de protección social complementaria hubiere adquirido el cedente; 2 . A los efectos de lo previsto en el presente artículo, se considerará que existe sucesión de empresa cuando la transmisión afecte a una entidad económica que mantenga su identidad, entendida como un conjunto de medios organizados a fin de llevar a cabo una actividad económica, esencial o accesoria; 3. Sin perjuicio de lo establecido en la legislación de Seguridad Social, el cedente y el cesionario, en las transmisiones que tengan lugar por actos intervivos, respon- 
los supuestos de sucesión de empresa. Finalmente y en cuarto lugar, dice el artículo que la transmisión no llevará aparejada obligación de pago de los créditos no satisfechos por el concursado antes de la transmisión, ya sean concursales o contra la masa, salvo que el adquirente la hubiera asumido expresamente o existiese disposición legal en contrario y sin perjuicio de lo dispuesto en el artículo 149.2. y que la exclusión descrita no se aplicará cuando los adquirentes de las unidades productivas sean personas especialmente relacionadas con el concursado.

derán solidariamente durante tres ańos de las obligaciones laborales nacidas con anterioridad a la transmisión y que no hubieran sido satisfechas. El cedente y el cesionario también responderán solidariamente de las obligaciones nacidas con posterioridad a la transmisión, cuando la cesión fuese declarada delito; 4. Salvo pacto en contrario, establecido una vez consumada la sucesión mediante acuerdo de empresa entre el cesionario y los representantes de los trabajadores, las relaciones laborales de los trabajadores afectados por la sucesión seguirán rigiéndose por el convenio colectivo que en el momento de la transmisión fuere de aplicación en la empresa, centro de trabajo o unidad productiva autónoma transferida. Esta aplicación se mantendrá hasta la fecha de expiración del convenio colectivo de origen o hasta la entrada en vigor de otro convenio colectivo nuevo que resulte aplicable a la entidad económica transmitida; 5 . Cuando la empresa, el centro de trabajo o la unidad productiva objeto de la transmisión conserve su autonomía, el cambio de titularidad del empresario no extinguirá por sí mismo el mandato de los representantes legales de los trabajadores, que seguirán ejerciendo sus funciones en los mismos términos y bajo las mismas condiciones que regían con anterioridad; 6 . El cedente y el cesionario deberán informar a los representantes legales de sus trabajadores respectivos afectados por el cambio de titularidad de los siguientes extremos: a) Fecha prevista de la transmisión; b) Motivos de la transmisión; c) Consecuencias jurídicas, económicas y sociales, para los trabajadores, de la transmisión, y d) Medidas previstas respecto de los trabajadores; 7. De no haber representantes legales de los trabajadores, el cedente y el cesionario deberán facilitar la información mencionada en el apartado anterior a los trabajadores que pudieren resultar afectados por la transmisión; 8. El cedente vendrá obligado a facilitar la información mencionada en los apartados anteriores con la suficiente antelación, antes de la realización de la transmisión. El cesionario estará obligado a comunicar estas informaciones con la suficiente antelación y, en todo caso, antes de que sus trabajadores se vean afectados en sus condiciones de empleo y de trabajo por la transmisión. En los supuestos de fusión y escisión de sociedades, el cedente y el cesionario habrán de proporcionar la indicada información, en todo caso, al tiempo de publicarse la convocatoria de las juntas generales que han de adoptar los respectivos acuerdos; 9. El cedente o el cesionario que previere adoptar, con motivo de la transmisión, medidas laborales en relación con sus trabajadores vendrá obligado a iniciar un período de consultas con los representantes legales de los trabajadores sobre las medidas previstas y sus consecuencias para los trabajadores. Dicho período de consultas habrá de celebrarse con la suficiente antelación, antes de que las medidas se lleven a efecto. Durante el período de consultas, las partes deberán negociar de buena fe, con vistas a la consecución de un acuerdo. Cuando las medidas previstas consistieren en traslados colectivos o en modificaciones sustanciales de las condiciones de trabajo de carácter colectivo, el procedimiento del período de consultas al que se refiere el párrafo anterior se ajustará a lo establecido en los artículos 40.2 y 41.4 de la presente Ley; 10. Las obligaciones de información y consulta establecidas en el presente artículo se aplicarán con independencia de que la decisión relativa a la transmisión haya sido adoptada por los empresarios cedente y cesionario o por las empresas que ejerzan el control sobre ellos. Cualquier justificación de aquéllos basada en el hecho de que la empresa que tomó la decisión no les ha facilitado la información necesaria no podrá ser tomada en consideración a tal efecto. (Artículo 44 redactado por el número dos del artículo segundo de la Ley 12/2001, 9 julio, de medidas urgentes de reforma del mercado de trabajo para el incremento del empleo y la mejora de su calidad («B.O.E.»10 julio).Vigencia: 11 julio 2001). 
Siguiendo con la venta de la que tratamos el segundo artículo a tener en cuenta es el 149, en el que en su segundo apartado se dice que cuando como consecuencia de la enajenación a que se refiere la regla $1 .^{a}$ del apartado primero, una entidad económica mantenga su identidad, entendida como un conjunto de medios organizados a fin de llevar a cabo una actividad económica esencial o accesoria, se considerará, a los efectos laborales y de Seguridad Social, que existe sucesión de empresa. En tal caso, el juez podrá acordar que el adquirente no se subrogue en la parte de la cuantía de los salarios o indemnizaciones pendientes de pago anteriores a la enajenación que sea asumida por el Fondo de Garantía Salarial de conformidad con el artículo $33^{10}$ del Estatuto de los Trabajadores.

10 Artículo 33 El Fondo de Garantía Salarial : 1. El Fondo de Garantía Salarial, Organismo autónomo adscrito al Ministerio de Empleo y Seguridad Social, con personalidad jurídica y capacidad de obrar para el cumplimiento de sus fines, abonará a los trabajadores el importe de los salarios pendientes de pago a causa de insolvencia o concurso del empresario. A los anteriores efectos, se considerará salario la cantidad reconocida como tal en acto de conciliación o en resolución judicial por todos los conceptos a que se refiere el artículo 26.1, así como los salarios de tramitación en los supuestos en que legalmente procedan, sin que pueda el Fondo abonar, por uno u otro concepto, conjunta o separadamente, un importe superior a la cantidad resultante de multiplicar el doble del salario mínimo interprofesional diario, incluyendo la parte proporcional de las pagas extraordinarias, por el número de días de salario pendiente de pago, con un máximo de ciento veinte días. (Número 1 del artículo 33 redactado por el número uno del artículo 19 del R.D.-ley 20/2012, de 13 de julio, de medidas para garantizar la estabilidad presupuestaria y de fomento de la competitividad («B.O.E.» 14 julio). Vigencia: 15 julio 2012); 2. El Fondo de Garantía Salarial, en los casos del apartado anterior, abonará indemnizaciones reconocidas como consecuencia de sentencia, auto, acto de conciliación judicial o resolución administrativa a favor de los trabajadores a causa de despido o extinción de los contratos conforme a los artículos 50, 51 y 52 de esta Ley, y de extinción de contratos conforme al artículo 64 de la Ley 22/2003, de 9 de julio, Concursal, así como las indemnizaciones por extinción de contratos temporales o de duración determinada en los casos que legalmente procedan. En todos los casos con el límite máximo de una anualidad, sin que el salario diario, base del cálculo, pueda exceder del doble del salario mínimo interprofesional, incluyendo la parte proporcional de las pagas extraordinarias. El importe de la indemnización, a los solos efectos de abono por el Fondo de Garantía Salarial para los casos de despido o extinción de los contratos conforme al artículo 50 de esta Ley, se calculará sobre la base de treinta días por año de servicio, con el límite fijado en el párrafo anterior. (Número 2 del artículo 33 redactado por el número dos del artículo 19 del R.D.-ley 20/2012, de 13 de julio, de medidas para garantizar la estabilidad presupuestaria y de fomento de la competitividad («B.O.E.» 14 julio). Vigencia: 15 julio 2012). 3. En caso de procedimientos concursales, desde el momento en que se tenga conocimiento de la existencia de créditos laborales o se presuma la posibilidad de su existencia, el juez, de oficio o a instancia de parte, citará al FOGASA, sin cuyo requisito no asumirá éste las obligaciones señaladas en los apartados anteriores. El Fondo se personará en el expediente como responsable legal subsidiario del pago de los citados créditos, pudiendo instar lo que a su derecho convenga y sin perjuicio de que, una vez realizado, continúe como acreedor en el expediente. A los efectos del abono por el FOGASA de las cantidades que resulten reconocidas a favor de los trabajadores, se tendrán en cuenta las reglas siguientes: Primera. Sin perjuicio de los supuestos de responsabilidad directa del organismo en los casos legalmente establecidos, el reconocimiento del derecho a la prestación exigirá que los créditos de los trabajadores aparezcan incluidos en la lista de acreedores o, en su caso, reconocidos como deudas de la masa por el órgano del concurso competente para ello en cuantía igual o superior a la que se solicita del FOGASA, sin perjuicio de la obligación de aquellos de reducir su solicitud o de reembolsar al FOGASA la cantidad que corresponda cuando la cuantía reconocida en la lista definitiva fuese inferior a la solicitada o a la ya percibida. Se- 
gunda. Las indemnizaciones a abonar a cargo del FOGASA, con independencia de lo que se pueda pactar en el proceso concursal, se calcularán sobre la base de veinte días por año de servicio, con el límite máximo de una anualidad, sin que el salario diario, base del cálculo, pueda exceder del doble del salario mínimo interprofesional, incluyendo la parte proporcional de las pagas extraordinarias. (Regla segunda del número 3 del artículo 33 redactada por el número tres del artículo 19 del R.D.ley 20/2012, de 13 de julio, de medidas para garantizar la estabilidad presupuestaria y de fomento de la competitividad («B.O.E.» 14 julio). Vigencia: 15 julio 2012 ).Tercera. En el supuesto de que los trabajadores perceptores de estas indemnizaciones solicitaran del FOGASA el abono de la parte de indemnización no satisfecha por el empresario, el límite de la prestación indemnizatoria a cargo del Fondo se reducirá en la cantidad ya percibida por aquellos. (Número 3 del artículo 33 redactado por el número ciento veinte del artículo único de la Ley 38/2011, de 10 de octubre, de reforma de la Ley 22/2003, de 9 de julio, Concursal («B.O.E.» 11 octubre), que introduce un nuevo apartado 3 en la disposición final decimocuarta de la Ley Concursal. Vigencia: 1 enero 2012). 4. El Fondo asumirá las obligaciones especificadas en los números anteriores, previa instrucción de expediente para la comprobación de su procedencia. Para el reembolso de las cantidades satisfechas, el Fondo de Garantía Salarial se subrogará obligatoriamente en los derechos y acciones de los trabajadores, conservando el carácter de créditos privilegiados que les confiere el artículo 32 de esta Ley. Si dichos créditos concurriesen con los que puedan conservar los trabajadores por la parte no satisfecha por el Fondo, unos y otros se abonarán a prorrata de sus respectivos importes. 5. El Fondo de Garantía Salarial se financiará con las aportaciones efectuadas por todos los empresarios a que se refiere el apartado 2 del artículo 1 de esta Ley, tanto si son públicos como privados. El tipo de cotización se fijará por el Gobierno sobre los salarios que sirvan de base para el cálculo de la cotización para atender las contingencias derivadas de accidentes de trabajo, enfermedad profesional y desempleo en el Sistema de la Seguridad Social. 6. A los efectos de este artículo se entiende que existe insolvencia del empresario cuando, instada la ejecución en la forma establecida por la Ley de Procedimiento Laboral, no se consiga satisfacción de los créditos laborales. La resolución en que conste la declaración de insolvencia será dictada previa audiencia del Fondo de Garantía Salarial. 7. El derecho a solicitar del Fondo de Garantía Salarial el pago de las prestaciones que resultan de los apartados anteriores prescribirá al ańo de la fecha del acto de conciliación, sentencia, auto o resolución de la Autoridad Laboral en que se reconozca la deuda por salarios o se fijen las indemnizaciones. (Párrafo $1 .{ }^{\circ}$ del número 7 del artículo 33 redactado por el apartado cinco del artículo 12 de la Ley 43/2006, de 29 de diciembre, para la mejora del crecimiento y del empleo («B.O.E.» 30 diciembre). Vigencia: 31 diciembre 2006). Tal plazo se interrumpirá por el ejercicio de las acciones ejecutivas o de reconocimiento del crédito en procedimiento concursal y por las demás formas legales de interrupción de la prescripción. 8. ... (Número 8 del artículo 33 suprimido, con efectos de 1 de enero de 2014 y vigencia indefinida, por la disposición final quinta de la Ley 22/2013, de 23 de diciembre, de Presupuestos Generales del Estado para el año 2014 («B.O.E.» 26 diciembre). Vigencia: 1 enero 2014 Efectos / Aplicación: 1 enero 2014). 9. El Fondo de Garantía Salarial tendrá la consideración de parte en la tramitación de los procedimientos arbitrales, a efectos de asumir las obligaciones previstas en este artículo. 10. El Fondo de Garantía Salarial dispensará la protección regulada en el presente artículo en relación con los créditos impagados de los trabajadores que ejerzan o hayan ejercido habitualmente su trabajo en España cuando pertenezcan a una empresa con actividad en el territorio de al menos dos Estados miembros de la Unión Europea, uno de los cuales sea España, cuando concurran, conjuntamente, las siguientes circunstancias: a) Que se haya solicitado la apertura de un procedimiento colectivo basado en la insolvencia del empresario en un Estado miembro distinto de Espańa, previsto por sus disposiciones legales y administrativas, que implique el desapoderamiento parcial o total del empresario y el nombramiento de un síndico o persona que ejerza una función similar. b) Que se acredite que la autoridad competente, en virtud de dichas disposiciones, ha decidido la apertura del procedimiento; o bien que ha comprobado el cierre definitivo de la empresa o el centro de trabajo del empresario, así como la insuficiencia del activo disponible para justificar la apertura del procedimiento. Cuando, de acuerdo con los términos establecidos en este apartado, la protección de los créditos impagados corresponda al Fondo de Garantía Salarial, éste solicitará información de la institución de garantía del Estado miembro en el que se tramite el procedimiento colectivo de insolvencia sobre los créditos 
Igualmente, para asegurar la viabilidad futura de la actividad y el mantenimiento del empleo, el cesionario y los representantes de los trabajadores podrán suscribir acuerdos para la modificación de las condiciones colectivas de trabajo. Posteriormente en el apartado tercero se dice que en el Auto de aprobación del remate o de la transmisión de los bienes o derechos realizados ya sea de forma separada, por lotes o formando parte de una empresa o unidad productiva, el juez acordará la cancelación de todas las cargas anteriores al concurso constituidas a favor de créditos concursales, salvo las que gocen de privilegio especial conforme al artículo 90 y se hayan transmitido al adquirente con subsistencia del gravamen.

\section{El Auto del Tribunal de Justicia de 28 de enero de 2015, sus repercusiones y la Ley 9/2015, de 25 de mayo, de medidas urgentes en materia concursal}

En fecha 28 de enero de 2015, la Sala Sexta del Tribunal de Justicia de la Unión Europea dicta un Auto que tiene por objeto una petición de decisión prejudicial planteada, con arreglo al artículo 267 TFUE, por el Juzgado de lo Mercantil n. 3 de Barcelona, mediante auto de 11 de diciembre de 2013, recibido en el Tribunal de Justicia el 27 de diciembre de 2013, en el procedimiento entablado por Gimnasio Deportivo San Andrés, S.L. en liquidación y en el que participan la Tesorería General de la Seguridad social (TGSS) y el Fondo de Garantía Salarial.

pendientes de pago de los trabajadores y sobre los satisfechos por dicha institución de garantía y pedirá su colaboración para garantizar que las cantidades abonadas a los trabajadores sean tenidas en cuenta en el procedimiento, así como para conseguir el reembolso de dichas cantidades. (Número 10 del artículo 33 introducido por el apartado tres del artículo único de la Ley 38/2007, de 16 de noviembre, por la que se modifica el texto refundido de la Ley del Estatuto de los Trabajadores, aprobado por el R.D. Legislativo 1/1995, de 24 de marzo, en materia de información y consulta de los trabajadores y en materia de protección de los trabajadores asalariados en caso de insolvencia del empresario («B.O.E.» 17 noviembre). Vigencia: 18 noviembre 2007). 11. En el supuesto de procedimiento concursal solicitado en Espańa en relación con una empresa con actividad en el territorio de al menos otro Estado miembro de la Unión Europea, además de Espańa, el Fondo de Garantía Salarial estará obligado a proporcionar información a la institución de garantía del Estado en cuyo territorio los trabajadores de la empresa en estado de insolvencia hayan ejercido o ejerzan habitualmente su trabajo, en particular, poniendo en su conocimiento los créditos pendientes de pago de los trabajadores, así como los satisfechos por el propio Fondo de Garantía Salarial. Asimismo, el Fondo de Garantía Salarial prestará a la institución de garantía competente la colaboración que le sea requerida en relación con su intervención en el procedimiento y con el reembolso de las cantidades abonadas a los trabajadores (Número 11 del artículo 33 introducido por el apartado cuatro del artículo único de la Ley 38/2007, de 16 de noviembre, por la que se modifica el texto refundido de la Ley del Estatuto de los Trabajadores, aprobado por el R.D. Legislativo 1/1995, de 24 de marzo, en materia de información y consulta de los trabajadores y en materia de protección de los trabajadores asalariados en caso de insolvencia del empresario («B.O.E.» 17 noviembre). Vigencia: 18 noviembre 2007). 
La petición de decisión prejudicial tenía por objeto la interpretación de la Directiva 2001/23/CE del Consejo, de 12 de marzo de 2001, sobre la aproximación de las legislaciones de los Estados miembros relativas al mantenimiento de los derechos de los trabajadores en caso de traspasos de empresas, de centros de actividad o de partes de empresas o de centros de actividad (DO L82, p. 16), siendo dicha petición suscitada en el marco de un procedimiento entablado por una sociedad limitada en liquidación respecto a la determinación de cuáles son las deudas de esta última que la entidad cesionaria podía no asumir tras la cesión de las actividades de la primera a la segunda.

Ante todo ello y en resume, tal y como recoge el Auto, las siete cuestiones planteadas por el órgano jurisdiccional remitente, que procedían examinarse conjuntamente, preguntaban, en esencia, si la Directiva 2001/23 debe interpretarse en el sentido de que se opone a que una normativa nacional como la controvertida en el asunto principal prevea o permita que, con ocasión de una transmisión de empresas, de centros de actividad o de partes de empresas o de centros de actividad, cuando el cedente sea objeto de un procedimiento de insolvencia, se autorice al cesionario a no asumir las cargas del cedente en relación con los contratos o las relaciones laborales, incluidas las relativas al régimen de la seguridad social, por cuanto estas deudas son anteriores a la fecha de transmisión de la unidad productiva y además se preguntaba el Juzgado si la circunstancia de que las relaciones laborales se hubieran extinguido antes de la mencionada fecha era relevante al respecto.

El Tribunal después de estudiar la normativa al respecto consideró que:

En primer lugar: La Directiva 2001/23 establece la norma de principio según la cual el cesionario se subroga en los derechos y obligaciones resultantes del contrato de trabajo o de la relación laboral existente entre el trabajador y el cedente en la fecha de la transmisión de la empresa. Tal como se desprende del tenor literal y de la estructura del artículo 3 de esta Directiva, la transmisión al cesionario de las cargas que, en el momento de la transmisión de la empresa, incumben al cedente debido a la circunstancia de que emplea trabajadores, comprende la totalidad de los derechos de estos últimos en la medida en que no se les aplique una excepción expresamente prevista por la misma Directiva. Por consiguiente, forman parte integrante de esas cargas no sólo los salarios y otras retribuciones que se deban a los trabajadores de la empresa de que se trate, sino también las cotizaciones al régimen legal de seguridad social correspondientes al cedente, puesto que tal carga resulta de los contratos o de las relaciones laborales que vinculan a este último. En efecto, como se desprende asimismo del artículo 2, apartado 1, de la Directiva 2001/23, un contrato de trabajo o una relación laboral implican, según dicha Directiva, una relación jurídica entre empresarios y trabajadores que tiene por objeto regular las condiciones de trabajo. 
En segundo lugar: Conforme al artículo 5, apartado 1, de la misma Directiva, esta norma de principio no es aplicable en el caso de que, como ocurre en el asunto principal, el cedente sea objeto de un procedimiento de insolvencia y se halle bajo la supervisión de una autoridad pública competente del Estado miembro de que se trate. En efecto, en tal caso, el pago de los créditos resultantes de la relación de los trabajadores con el empresario en caso de insolvencia queda garantizado a estos últimos en virtud de la Directiva 80/987.

En tercer lugar: No obstante esta excepción enunciada por la Directiva 2001/23, el artículo 5, apartado 1, de ésta faculta a cada Estado miembro a aplicar en particular el artículo 3 de la mencionada Directiva a una transmisión de empresa en el marco de un procedimiento de insolvencia abierto respecto de un cedente. Cuando un Estado miembro hace uso de esta facultad, el apartado 2, letra a), del mismo artículo 5 dispone que dicho Estado puede establecer una excepción al artículo 3, apartado 1, de esta Directiva en el sentido de que no se transfieran al cesionario las cargas correspondientes al cedente en la fecha de la transmisión o de la apertura del procedimiento de insolvencia, en virtud de los contratos o de las relaciones laborales, siempre y cuando exista en ese Estado miembro una protección al menos equivalente a la establecida por la Directiva 80/987, que exige que se instaure un mecanismo de garantía del pago de los créditos adeudados a los trabajadores conforme a los contratos o relaciones laborales acordados con el empresario insolvente. Esta posibilidad de establecer una excepción permite no sólo garantizar el pago de los salarios de los trabajadores afectados, sino también mantener el empleo garantizando la supervivencia de la empresa en dificultades.

En cuarto lugar: Con arreglo al artículo 8 de la Directiva 2001/23, los Estados miembros pueden prever y aplicar cualquier otro régimen en materia de transmisión de empresas, siempre y cuando éste sea más favorable para los trabajadores que el establecido por la referida Directiva. En efecto, esta manera de proceder es conforme con el objetivo perseguido por la misma Directiva, tal como se recuerda en el apartado 34 del presente auto. Así, un Estado miembro no queda privado de la facultad de aplicar el artículo 3, apartado 1, de dicha Directiva, aun en el supuesto de que un operador adquiera una empresa en situación de insolvencia.

En quinto lugar: Tanto del tener literal de la Directiva 2001/23 como del régimen que ésta establece resulta que, aparte de la obligación impuesta a los Estados miembros de proteger los derechos adquiridos o en curso de adquisición de los trabajadores que hayan dejado ya el centro de actividad del cedente en el momento de la transmisión, en lo que se refiere a las prestaciones mencionadas en el artículo 3, apartado 4, letra b), de dicha Directiva, el legislador de la Unión no ha previsto normas en relación con las cargas del cedente derivadas de contratos o relaciones laborales que ya se hubieran extinguido en la fecha en que 
tiene lugar la transmisión. No obstante, por la mismas razones que las enunciadas en el anterior apartado, nada impide a un Estado miembro disponer la transmisión de tales cargas al cesionario.

Finalmente y en base a las cinco consideraciones expuestas anteriormente, el Tribunal respondió de la siguiente forma:

a) En el supuesto de que, en el marco de una transmisión de empresa, el cedente sea objeto de un procedimiento de insolvencia que esté bajo la supervisión de una autoridad pública competente y el Estado miembro de que se trate haya optado por hacer uso del artículo 5, apartado 2, de la mencionada Directiva, ésta no se opone a que dicho Estado miembro disponga o permita de las cargas que, en el momento de la transmisión o de la apertura del procedimiento de insolvencia, resulten para el cedente de contratos o relaciones laborales, incluidas las relativas al régimen legal de la seguridad social, no se transfieran al cesionario, siempre que dicho procedimiento garantice una protección de los trabajadores como mínimo equivalente a la establecida por la Directiva 80/987, si bien nada impide que dicho Estado miembro prevea que tales cargas deban ser soportadas por el cesionario aun en caso de insolvencia del cedente;

b) Sin perjuicio de las disposiciones previstas en su artículo 3, apartado 4, letra b), dicha Directiva no establece obligaciones en cuanto a las cargas del cedente resultantes de contratos o relaciones laborales que ya se hubieran extinguido antes de la fecha de la transmisión, pero no se opone a que la normativa de los Estados miembros permita la transferencia de tales cargas al cesionario.

Así las cosas, algunos periódicos económicos ${ }^{11}$ españoles se apresuraron a informan manifestando que el Tribunal de la UE había dictado una resolución judicial en la que se establecía que la deuda laboral de empresas en concurso no se heredaba e incluso mencionaban declaraciones de algún despacho de abogados en las que se indicaba que se celebraba el sentido del auto y se esperaba que el Gobierno lo tuviera en cuenta durante la tramitación de la norma en las Cortes, sin embargo había otros abogados que no eran tan optimistas puesto que manifestaban que el fallo estipulaba lo que ya decía la anterior Ley Concursal espańola y que la reforma del ministro Guindos había establecido lo contrario pero amparándose en las excepciones que prevé la Directiva, sin embargo también se hacían menciones a que como la obligación de heredar la deuda laboral im-

11 Véase por ejemplo el diario Expansión del jueves 29 de enero de 2015 cuyo titular en la página 31 era. «El Tribunal de la UE: La deuda laboral de empresas en concurso no se "hereda"» y continuaba posteriormente diciendo, entre otras manifestaciones: «El comprador de una empresa en concurso no tiene que heredar la deuda de ésta con la Seguridad social». 
plicaba destrucción de empleo, no era completamente descartable que hubiera cambios.

Sin embargo, había un hecho que estaba claro y en el que todos coincidían y es que en la Ley Concursal vigente hasta septiembre de 2014 las deudas laborales de una empresa en concurso no se heredaban pero con el nuevo Real Decreto-Ley de medidas urgentes en materia concursal las cosas habían cambiado y se establecía que las deudas con la Seguridad Social se heredaban.

En el $\mathrm{BOE}^{12}$ número 125 de 26 de mayo de 2015, se publica la Ley 9/2015, de 25 de mayo de medidas urgentes en materia concursal en el que en lo referente a lo anteriormente expuesto las cosas quedaban igual.

\section{Conclusiones}

El antiguo artículo 149.2 de la Ley Concursal y el actual artículo 149.4 de la Ley 9/2015 traen a cuenta dos temas fundamentales en relación a la llamada deuda laboral, en primer lugar en cuanto a la competencia del Juez del Concurso para pronunciarse respecto a la sucesión de empresa y ello en cuanto a si lo era o no sólo a efectos meramente prejudiciales y en segundo lugar en cuanto a la propia sucesión de empresas a efectos laborales y de la seguridad social y sus consecuencias en cuanto a la llamada deuda laboral.

En cuanto al primer tema los Jueces de lo Mercantil en Cataluña se habían ya posicionado a favor de entender que el Juez del concurso era el competente para pronunciarse respecto a la sucesión de empresa, puesto que su competencia no se limitaba a aprobar la venta de la unidad productiva sino que era mayor, ya que alcanzaba a tener que pronunciarse sobre los efectos que se derivaban de la venta y es en esa venta donde la Ley Concursal también hablaba de una venta sin cargas ni gravámenes y de una sucesión de empresa a efectos «laborales y de la seguridad social» por lo que es evidente la competencia objetiva de dichos jueces para pronunciarse sobre dichos temas y ello ha sido refrendado posteriormente tanto en el Real Decreto-Ley como en la posterior Ley.

Del Auto del Tribunal Europeo del que hemos hablado anteriormente, por otro lado, se desprendía que al no haber ningún precepto en la Ley Concursal ni en otra disposición sobre las deudas de la concursada en cuanto a la AEAT o al FOGASA, sobre éstas deudas no se entendería que hay sucesión de empresa, ahora bien, en cuanto a la sucesión de empresa, ésta deberá entenderse a «efectos laborales y de la seguridad social» y sólo en cuanto a los contratos que estén en vigor y se subrogue el adquirente y no en cuanto a las deudas laborales y de

12 Boletín Oficial del Estado (España). 
la seguridad social que la concursada tenga frente al resto de trabajadores que no entren en la subrogación y ello en base al artículo 5 de la Directiva 2001/23/CE y la interpretación realizada en el Auto del Tribunal Europeo del que ya hemos hablado en el apartado anterior interpretándose que la normativa concursal española cuando habla de venta de una unidad productiva entiende que hay sucesión de empresa a efectos laborales y de la seguridad social pero no determina o diferencia si la deuda es la generada con los trabajadores que siguen o con todos y al no realizar la diferencia es cuando debemos aplicar la Directiva comunitaria que habla de los contratos de trabajo al tiempo de la venta, pero «en vigor» y ello implica que sean sólo los contratos en los que se subroga el adquirente de la empresa o unidad productiva y ningún otro.

\section{Bibliografía}

Borjabad Gonzalo, Primitivo (2006): «Derecho Mercantil. Vol. II»,Lleida, EURL. Borjabad Gonzalo, Primitivo (2009): «Derecho Mercantil Vol. I.1».Lleida, EURL. Borjabad Gonzalo, Primitivo (1998): «Derecho Mercantil Vol. I».Lleida, EURL.

Desdentado Bonete, Aurelio (2004): «La Seguridad Social en la nueva Ley Concursal». Revista del Ministerio de Trabajo y Asuntos sociales-49, pp. 13-33.

FMI (2014) «Consulta del artículo IV de 2014 con España. Declaración Final de la Misión"

Gómez Martín, Fernando (2004): «Créditos tributarios y de la seguridad social en sede concursal» disponible en http://www.grupofgm.com/idb/publicaciones.

International Monetary Fund (2014) Consulta del Artículo IV de 2014 con España. Declaración Final de la Misión. Madrid.

International Monetary Fund (2014). «Evolución reciente, perspectivas y prioridades para las políticas» disponible en http://www.imf.org.

Malagón Ruiz, Pedro José (2014). «La transmisión de Unidades productivas» disponible en http://www.icjce-euskadi.com/PonenfiasForoConcursal2014

Serraller, Mercedes (2015): «El Tribunal de la UE: La deuda laboral de empresas en concurso no se «hereda»", Expansión, Madrid, p.31.

Tamayo Alba (2014) «La venta de las unidades productivas en el concurso de acreedores» disponible en www.estudioconcursal.com

XSIM (2014) «Las recomendaciones del FMI para España» disponible en http:// salaimartin.com/randomthoughts/item/725-las-recomendaciones-del-fmi-paraespa \%C3\%B1a.html. 